\title{
Having Life More Abundantly: \\ Caring for the Body, Mind and Spirit
}

\author{
Thomas D. Jeitschko \\ Department of Economics \\ Michigan State University \\ East Lansing, Michigan \\ USA \\ Séamus O'Connell \\ Faculty of Theology \\ Maynooth College \\ County Kildare \\ Ireland
Rowena A. Pecchenino
Department of Economics
East Lansing, Michigan
USA \\ Michigan State University
}

30 May 2005

We would like to thank Enda McDonagh, David Madden, Finbarr Bradley, Ayman Reda, and the seminar participants at the University of Nottingham, Drexel University, Michigan State University and the 2005 Irish Economic Association Meetings for their comments. All errors are ours alone. 


\section{Having Life More Abundantly:}

\section{Caring for the Body, Mind and Spirit}

An individual's health can be subdivided into three categories: physical health, mental health, and psychic health. Extensive empirical work has shown that the health of the spirit, that is, psychic health, is an important correlate of the health of the body and the mind. To trace the linkages between one's choices concerning the disposition of one's income and time and one's health and well-being broadly defined, we develop a model which allows us to compare individuals with differing spirituality characteristics. While subjective well-being is increasing in one's spirituality, the more spiritual may not be healthier than their less spiritual peers. Those whose faith provides a superior ability to cope with stress and illness, via spiritual capital or a sense of coherence, will have both higher levels of health and subjective well-being. But, these positive health effects are not directly amenable to exploitation by public policy - faith, although nurtured by the Church, cannot be mandated by the State.

JEL: I190

Key words: Spirituality, Spiritual Capital, Sense of Coherence, Health and Well-being 


\section{Having Life More Abundantly: \\ Caring for the Body, Mind and Spirit}

\section{Introduction}

An individual's health can be subdivided into three categories

Physical health - well-being of the body

Mental health - well-being of the mind

Psychic health - well-being of the spirit.

The first type of health is overseen by the medical practitioner, the internist, the oncologist, the osteopath, the chiropractor, etc., whose concern is with the efficient functioning of the body. The second type of health is overseen by the mental health practitioner, the social worker, the psychiatrist, the psychologist, etc., whose concern is with the efficient functioning of the mind, of the balance of emotions, of one's ability to cope with temporal realities. The last type of health is overseen by the priest, the rabbi, the lama, the minister, the imam, the healer, etc., whose concern is with one's spirituality, with one's relationship with God and one's fellow man.

For the most part, we treat these categories of health as largely separate and distinct, while we recognize they are not (see, e.g., Koenig, et al. 2001, Miller and Thoresen 2003, and Powell, et al. 2003). Attempts have been made by the medical profession to bridge the divide by bringing the spiritual to bear on the physical and mental: courses on religion, spirituality, and medicine are common in U.S. medical schools (Koenig, et al. 2001), and pastoral care is provided in many hospitals (Driscoll, 2003). Yet health policy and health insurance has largely eschewed the essential connections. Mental health coverage is often severely restricted, e.g., the number of covered visits is restricted in ways that physical health coverage is not. And little provision is 
made for the spirit. Yet it is the health of the spirit that has repeatedly been shown to be an important correlate, if not determinant, of the health of the body and the mind. ${ }^{1}$

To trace the linkages between one's choices and one's health and well-being, the abundance of one's life (NRSV, John 10:10), we develop a model which builds on Bednarek, Jeitschko, and Pecchenino (2004) and Bednarek, Pecchenino and Stearns (2005). The model allows us to compare individuals with differing spirituality characteristics. Quotations from Christian scripture are used to illustrate these modeling choices. The model takes the complexities and competing demands of modern life seriously: cultural and sociological demands on one's time and one's income compete with one's desire for health and well-being. Individuals divide their time among work, leisure, exercise and other healthy activities, and spiritual pursuits. They divide their income among consumption goods, medical care, donations to support their religious community and its causes, or purchases of goods and services that deepen their spiritual life.

The individual must decide how to allocate his time. But, time spent in one way may affect the benefit of spending time in other ways. Thus, time spent at work may be stressful thereby reducing the effectiveness of exercise and other healthy activities, or it may entail health maintaining exercise, reducing the need to devote additional time to health. Time spent in spiritual pursuits - attendance at services, in prayer, in meditation, etc., may also have salutary or, perhaps, pathological effects, again reducing, or increasing, the need to spend time in health enhancing activities rather than at leisure. Further, there may be a minimum amount of time one needs to spend at leisure before one gets any benefit from the time spent - the time needed to unwind, to sleep, to meet one's social obligations.

When allocating one's income, the more goods one consumes the less income that remains to purchase physical and mental health enhancing medical care or to make psychic health enhancing

\footnotetext{
${ }^{1}$ Thus, Hummer, et al. (1999), for example, find a seven year difference in life expectancy at age twenty between those who attend religious services more than once a week and those who never attend.
} 
(altruistic) donations to one's religious community, etc. The benefit of such expenditures depends not on the level of spending, but the level relative to one's income - the poor may be more generous than the rich, and thus may reap larger rewards (see Luke 21:1-4). But, there may be no benefit to consuming goods unless some minimum level of consumption is exceeded. This level may represent a physiological necessity, or it may represent a sociological or cultural one (keeping up with the Joneses), or it may represent a change in one's needs in response to stress comfort food or retail therapy.

While time spent in spiritual pursuits affects one's physical and mental health, psychic well-being is augmented by spiritual activities (time) and spirituality enhancing expenditures (money). However, individuals differ in their ability to achieve psychic well-being as a result of extrinsic and intrinsic differences in their spirituality, and their place in their faith community which gives definition to their relationship with God and their fellow man. The relationship itself may exhibit increasing, constant, or decreasing returns. But, one's spirituality must vie with the more mundane. To spend more time in prayer, for example, one must give up time spent at leisure or in physical and mental health enhancing activities: one must, therefore, compare marginal benefits across alternate uses of one's time. That is, one must balance the competing demands of body, mind and soul given one's limited resources. In this paper we explore just how one does this given the internal and external forces at work.

The paper proceeds as follows. Section II contains a somewhat idiosyncratic literature review. Its purpose is to show the breadth of research on the links between spirituality and health. In Section III the model is presented. The main results are derived and discussed in Section IV. In Section $\mathrm{V}$ we examine whether there is a role for public policy in promoting the link between spiritual health and physical/mental health. Section VI concludes. 


\section{Review of the Literature}

Many disciplines, among them medicine, psychology, sociology, and religious studies, have examined the relationship between spirituality or devoutness and physical and mental health. Some studies are narrowly focused, and attempt to answer specific questions, such as the effect of faith on longevity (an indicator of health), others are broadly focused and ask questions such as what makes people well (rather than asking what makes people sick). Some studies examine the delivery of health care to determine if spiritual/pastoral care should be an integral component of any treatment regime, asking, implicitly, if those who receive such care heal better. Some examine why some faith communities enjoy good health. Some ask if the more spiritual among us are happier. While this list is by no means exhaustive, it gives some indication of the breadth of the quest to uncover the connections between religion and health.

The most comprehensive review of the literature on religion and both physical and mental health is found in Koenig, et al. (2001) in which over 1,600 studies are systematically reviewed. An historical time line relating religion, science and medicine is provided which is followed by a brief history of thought on the salutary and deleterious effects of religion on health. Thereafter the literature is reviewed. The 1,600 studies in their sample examine the relationship between religion and physical health, both generally and specifically, between religion and mental health, between religion and the use of healthcare, and between religion and the provision of healthcare. They conclude that, while the studies reviewed vary in rigor and scientific merit, the preponderance of the evidence suggests that faith, somehow defined, is salutary: religiosity, spirituality, pastoral care, etc., lead to better health outcomes.

In the late 1970s the medical sociologist Aaron Antonovsky published Health, Stress, and Coping (1979). It contains the beginning of his work aimed at determining what makes people well rather than what makes people sick. In his 1987 book, Unraveling the Mystery of Health: How 
People Manage Stress and Stay Well, he links wellness to what he calls the sense of coherence which he defines as "a global orientation that expresses the extent to which one has a pervasive, enduring though dynamic feeling of confidence that (1) the stimuli deriving from one's internal and external environments in the course of living are structured, predictable, and explicable; (2) the resources are available to one to meet the demands posed by these stimuli; and (3) these demands are challenges, worthy of investment and engagement” (Antonovsky, 1987, p. 19). One's religious beliefs or faith may provide this sense of coherence, thus providing the individual with the means to navigate successfully through life.

Antonovsky's main concern was what makes people well, not whether religious beliefs were strongly correlated with a positive sense of coherence, and so this link, while suggested, is not examined directly in his work. Other sociologists and psychologists have looked more directly at the relationship between health or well-being, as externally or subjectively measured, and religion. Meta-analyses, such as Powell, et al. (2003), and reviews of the epidemiological literature, such as Miller and Thoresen (2003), find positive linkages between religious practice and health. Kark, et al. (1996) found that Jews living on religious kibbutzim lived longer, and thus were healthier, than their secular counterparts. The main difference between these two groups' lives was religious observance.

When subjective well-being is the measure of health, Ellison (1991) finds that strong religious faith leads to higher levels of life satisfaction and happiness, and a greater ability to deal effectively with traumatic life events. Cohen (2002) finds that while spirituality is positively related to happiness or life satisfaction, this is more strongly the case for Christians than for Jews. Thus, one's measure of spirituality, or aspects thereof, may generate differing results depending on the question asked and the groups studied. Swinyard, et al. (2000) examine whether materialism or religiousness is the better road to happiness. They find it is the latter both for Americans and Singaporeans, the two nationalities chosen for the study since culturally 
materialism is considered a stronger force in Singapore than in the United States. ${ }^{2}$ Even studies not specifically examining the religion/health linkage report on it. In David Snowdon's epidemiological study of the School Sisters of Notre Dame (2001) which investigated the causes of Alzheimer's disease, he chose to study the members of a religious order because of the similarities of their lives. He asserts, however, that their spirituality improved their health. ${ }^{3}$ Many of these studies delve deeply into the health/religion duality, and they address why religion may generate these benefits, but they do not explain how one comes to be religious or whether individuals are cognizant of the link between their spirituality and their health.

The discipline of psychology has been divided about the effects of religion on mental health almost from its inception. Freud (1907) clearly thought religious practice harmful and likened it to obsessive behavior, while Jung (1933) found religious belief to be a key to psychological healing and recovery. Van der Horst (1955) echoes Jung. For him, one can not hope to improve the mental health of an individual without knowing the state of his soul. Recent work, such as the survey by George, et al. (2000) and Hackney and Sanders' (2003) meta-analysis, while being more empirical and less philosophical, tend to favor Jung's view rather than Freud's.

The debate over religion and health spills over onto the provision of health care. Joseph Driscoll (2003, 2002) asks the following questions: Are hospital chaplains healthcare professionals, and are they and should they be an integral part of a hospital patient's healthcare team? Does the pastoral care provided by the chaplain in conjunction with the clergy aid in and speed the patient's recovery process? Answers to these questions are important as hospitals work to contain

\footnotetext{
${ }^{2}$ In their study of subjective well-being, economists Blanchflower and Oswald (2004) find that being religious increases one's happiness, but choose not to include the religiosity variable in their preferred regressions. Oswald (1997) examines what makes people unhappy, but again chooses not to use religious practice as a control.

${ }^{3}$ Snowdon states that one of the factors that led to the sisters' health and longevity was "the deep spirituality that these women share." (p. 202)
} 
and cut their costs. But answers to these questions may also have public policy ramifications if medical treatment coupled with pastoral care can lead to better health outcomes.

What almost all of these studies briefly reviewed above have in common is their empirical nature. They seek a relationship between health or well-being and spirituality. Generally one is found and it is positive. Economists have been noticeably absent from this debate. This is somewhat surprising since the literature on health economics is large and one of the most rapidly growing areas of research within economics. And what is missing from this literature is an analysis of the choices individuals make over the disposition of their resources of time and money into spiritual and temporal uses. An hour in prayer or meditation is an hour not spent exercising or at leisure. A dollar donated to the church or synagogue is a dollar not spent on consumption goods or medical care. How these choices are made, the forces that affect these choices, and the trade-offs they entail, are the concerns this paper addresses.

\section{The Model}

We model the choices of an individual. That individual may be an agnostic who rejects the spiritual, a spiritual individual who is not a member of a religion, or a member of a faith community. ${ }^{4}$ Since our interest is in the link between spirituality and health, we focus mainly on the last two types of individuals.

While there is no universally agreed upon definition of spirituality (Marmion, 1998), we understand spirituality to mean "the experience of consciously striving to integrate one's life in terms not of isolation and self-absorption but of self-transcendence toward the ultimate value one

\footnotetext{
${ }^{4}$ One may argue that individuals' spirituality characteristics are distributed along a continuum, and our model allows for this. However, we distinguish the three distinct sets to make comparisons more straightforward.
} 
perceives" (Schneiders, 1986, p.266). For the religious (Christian) individual, "this experience is neither received nor lived in isolation. Christian life in the Spirit takes place in an ecclesial context; hence... Christian spirituality is that of a group, whether the family, the parish, or specialized groups giving rise to various schools or traditions of spirituality" (Marmion, p. 18). This does not exclude the fact that within groups there are some, who because of their own experience, insight or wisdom go in a new direction. Within groups there are leaders and guides, masters (gurus), those who innovate yet may not always be followed. However, from the perspective of the present model, they are members of the group, even if they eventually move outside the group. Thus, spirituality for the religious individual is developed and enhanced within a community of which the individual is a member. For the nonreligious individual, the community component of spirituality is significantly attenuated.

If the individual is a member of a faith community, he pursues his spirituality both alone and in communal religious practice. He contributes to the community in terms of time spent in spiritual pursuits, some of which are community rather than privately focused, and in terms of donations or tithes. ${ }^{5}$ The individual benefits from membership in the community in terms of a sense of coherence that gives him the means to effectively cope with the complexities of life. This sense of coherence has both internal and external components such that his faith provides him a framework within which to understand and successfully navigate his life, and his faith community provides implicit and explicit benefits of membership, from a sense of belonging and presence in prayer inherent in communal religious practice, to pastoral care and economic support in times of need to assist him. ${ }^{6}$ In this paper we do not model the explicit interaction between the individual

\footnotetext{
${ }^{5}$ Clearly, a member of a faith community may choose to dedicate time, but not money, or money but not time, or both time and money to his community as part of his spiritual development. What is important for our purposes is that the individual defines himself as a member of a community; the strengths of those bonds are determined by both the actions of the individual toward the community and the community toward the individual. These bonds are subsumed in the parameters of the model.

${ }^{6}$ The benefits of group membership, often referred to as social capital - "an instantiated informal norm that promotes cooperation between two or more individuals" (Fukuyama, 1999, p.1), come from the reduction
} 
and the community. Rather, we suggest where the effects of the community on the individual will be realized in terms of parameter values. In a companion piece, we model both the community and the individuals that comprise it.

An individual's well-being is defined by the composite function

$$
\chi\left(t^{s}, \bar{s}\right) U\left(c, t^{\ell}, h\right)
$$

Here $U$ is a conventional utility function defined over consumption, $c$, leisure, $t^{\ell}$, and health, $h$. The function $\chi$ represents the individual's spirituality which is enhanced by time spent in spiritual pursuits, $t^{s}$, and donations or tithes, $\bar{s}$, made to the community. Implicitly, in conventional analysis, the spirituality function, $\chi$, is assumed to be a constant.

Standard economic thought defines an agent's preferences over things that are more or less readily measurable - the consumption of goods, leisure time, the quality of one's health, while the concerns of moral theology over the past two thousand years have "seesaw[ed] back and forth between a singular concern for sin, external actions and universal claims on the one hand, and a more inclusive notion of the natural law, the formation of internal dispositions, and an appreciation for concretely specific notions of moral truth on the other" (Harrington et al., 2003, pp. 7-8). Thus, from a theological perspective, human living is examined not only from the standpoint of what it is in itself, but also from the perspective of what God has "created" human life to be, of how God "envisions" authentic and fulfilled human life. Consequently, well-being from the perspective of theology would be defined more by determining whether an individual is living a virtuous life, where virtue is seen as how one's actions will influence the type of person one wishes to become. Should he be Christian - a believer in Christ - does he take the actions he ought to in order to live the type of life of one who follows Christ (Gula, 1989; O'Connell, 
1990)? In this setting, one's motives, one's reasons for taking an action, for living in a particular way, may be more important than the resources expended and consumed in terms of well-being achieved. Thus, it may be considered good that one's actions benefit others, but if one took those actions to improve one's own social standing rather than to aid those in need, then one's motives are inconsistent with moral living or spiritual growth.

In the setting of this model motives are primitives ${ }^{7}-$ the individual desires to live virtuously (Matt 5:21-6:1 or 6:6) and takes actions to achieve that outcome. The strength of that desire or that dedication to living a virtuous life is reflected in the parameters of the spirituality function, $\chi$, and in some of the parameters of the utility function, $U$. This is a crude representation which ignores the essentially dynamic nature of living virtuously. ${ }^{8}$ It also ignores that people can change. However, it does allow us to make comparisons across individuals who are identical up to the strength/centrality of their faith in guiding their lives, and this is the aim of this paper.

The individual components of the model can be understood in the following way. Even when strongly motivated to live virtuously, one must nurture one's spirituality. Living out of one's faith takes both time (in prayer [Matt 6:5-8; Luke 18: 3-5], in religious observance [Deut 10:1222], in charitable activities [Matt 6:1-4; Luke 10:30-37] etc.), and money (in donations to support the community [Acts 2:44-45], and to support one's spiritual life [Mark 10:17-22]) to achieve. How much money depends on what one has (Luke 21:1-4; Lev 27:30-32), thus the value of one's donation is taken relative to one's income. It is worth considering the motivation and framework

\footnotetext{
${ }^{7}$ The spirituality function in this paper is examined from the dynamics of a Christian moral theology with scriptural references used for motivational purposes. Similar functions could be developed using Jewish, Islamic, or other religious ethical and moral reasoning as a basis. It might also be noted that within Christianity, different Christian traditions approach moral theology and ethical reasoning with differing emphases which may sometimes be seen as different moral theologies.

${ }^{8}$ While one could argue that time and money spent today on one's spirituality is an investment in one's afterlife, and, as with any investment, one could invest less today or even disinvest today while planning to make up for it tomorrow, like St. Augustine, who prayed, "give me chastity and continence, but not yet". However, in the parable of the homeowner and the thief, Matt 24:43-44, one must live as if each day is one's last - there may be no tomorrow in which to redeem oneself.
} 


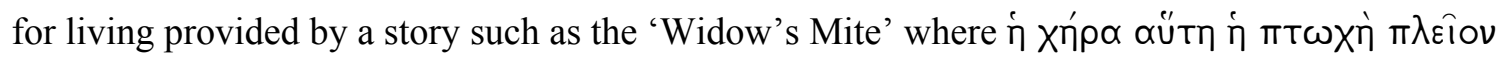

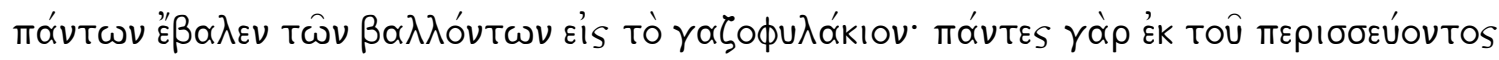

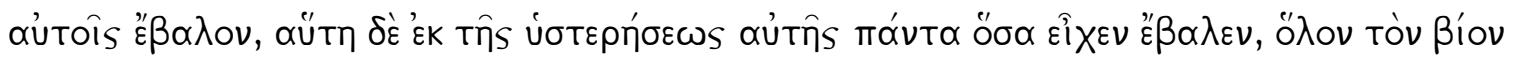
๔ưTกิs (Mark 12:43b-44) (the poor widow herself gave more than all those giving to the treasury, for all gave out of what they had left over but she, out of her want, gave everything that she hadall her life). ${ }^{9}$ The more one gives and gives altruistically (Col 3:14) to benefit the community, the common good, rather than oneself, all else equal, the better one's spiritual well-being.

Thus, we let

$$
\chi\left(t^{s}, \bar{s}\right)=\left(a_{1}+t^{s}\right)^{g_{1}}\left(a_{2}+\bar{s}\right)^{g_{2}}, \quad g_{1} \geq 0, g_{2} \geq 0, a_{1} \geq 1, a_{2} \geq 1,
$$

with $\bar{s}$ being measured relative to the individual's overall income.

One's ability to transform time and money into spiritual wellness depends on a multitude of intrinsic and extrinsic factors, ${ }^{10}$ parameterized by the exponents $g_{l}$ and $g_{2}$, where $g_{1}$ may be interpreted as an index of spirituality and $g_{2}$ as an index of altruism. ${ }^{11}$ What these functional relationships are meant to capture is that neither time nor money alone are adequate to achieve spiritual wellness. Some may see greater, perhaps even increasing, returns to spiritual activities; there is no reason to presume that time or money spent in spiritual activities exhibits decreasing

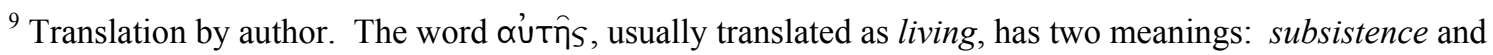
life. The word play is intended by the Evangelist. Both interpretations of the text are consistent with and include the connection we make between the act of giving (either of oneself, time, or money) being valued relative to what one has rather than how much it increases what the recipient obtains.

${ }^{10}$ For example, some attend religious services or make donations to religious organizations not to improve their spiritual well-being but rather to make business contacts and thereby improve their material wellbeing. Thus, their expenditures of time and money may have little effect on their spirituality and are better considered part of their work or leisure time and their consumption expenditures.

${ }^{11}$ These indexes could be positively related to the spiritual guidance and sense of coherence provided by membership in a religious community via ritual and the clergy. The quality of this guidance will depend on the religion's doctrinal stability, moral authority, etc., which we capture below with the parameter $\rho$.
} 
returns at the margin (Putnam, 2000). Yet some may see very little return. ${ }^{12,13}$ The parameters $a_{1}$ and $a_{2}$ ensure that individual welfare is increasing in spirituality and altruism.

Spiritual wellness does not exist independently of physical and mental wellness, ${ }^{14}$ and this is reflected in the functional form of $U$.

$$
\begin{aligned}
& U\left(c, t^{\ell}, h\right)=\left(c-\xi\left(g_{1}\right)\right)^{\alpha}\left(t^{\ell}-\lambda\left(g_{1}\right)\right)^{\beta} h^{v}, \\
& 0<\alpha, \beta, v<1, \quad \alpha+\beta+v \leq 1, \quad \xi(0)>0, \lambda(0)>0, \quad \xi^{\prime} \leq 0, \lambda^{\prime} \leq 0 .
\end{aligned}
$$

Individuals need to consume to live and thus must consume at least $\xi\left(g_{1}\right)$ units of goods before feeling the benefit of that consumption. What determines the requisite level of consumption could be physiological - minimum levels of food and shelter - it could additionally have cultural or sociological aspects - keeping up with the Joneses - or psychological aspects - stress relief through comfort food or retail therapy. We assume that the more spiritual an individual is (i.e., the higher $g_{1}$ ), the less susceptible he is to social or psychological pressures. ${ }^{15}$ It is possible that at a high enough price of consumption, $p^{c}$, even this minimum cannot be obtained. We will abstract from this case. Individuals also need to spend time at leisure to live and thus must spend at least $\lambda\left(g_{1}\right)$ units of time at leisure before feeling its benefit. What determines the requisite level of leisure could be physiological - the need for sleep - it could, in addition, have cultural or sociological aspects - meeting one's social obligations - or psychological aspects - stress relief

\footnotetext{
${ }^{12}$ It is possible that for low levels of spiritual activity the return is negative and only through perseverance will one achieve positive returns from his efforts. See Interior Castle, by St. Teresa of Avila, and The Cloud of Unknowing, where the difficulties of spiritual growth through contemplative prayer are explained. ${ }^{13}$ What this analysis leaves out is that "for God all things are possible" (Mark 10:27), and that "many who are first will be last, and the last will be first" (Mark 10:31). That is, just being virtuous or righteous is never, in the final analysis, enough. From a Christian or Jewish perspective, what matters in the end is the grace of God.

${ }^{14}$ The author of the Cloud of Unknowing warns his pupils that "this work [contemplative prayer] demands a relaxed, healthy, and vigorous disposition of both body and spirit." p.101.

${ }^{15}$ For example, Sherman argues that by "[A]cting on our allegiance to the Lord of the Sabbath, we are both allowed and obliged to say "no" to those ceaselessly encroaching activities that would rob us of the peace that God's time grants us." (Sherman, 2005, p.50)
} 
through idleness. ${ }^{16}$ We again assume that the more spiritual an individual is (i.e., the higher is $\left.g_{1}\right)$, the less susceptible he is to social or psychological pressures.

Finally, individuals attend to their physical and mental health. They do this by purchasing medical care, such as having routine checkups, purchasing pharmaceuticals, etc. and spending time in healthy activities, such as exercise. Thus, health is an increasing function of medical expenditures, $m$, and exercise, $e$.

$$
\begin{aligned}
h=h_{0}+\mu(\rho) m+\gamma(\rho)\left(e-\hat{e}\left(t^{s}, w\right)\right), & \\
& h_{0} \geq 0 ; \mu(0)>0, \mu^{\prime} \geq 0 ; \gamma(0)>0, \gamma^{\prime} \geq 0 .
\end{aligned}
$$

To benefit from healthy activities they must spend at least $\hat{e}\left(t^{s}, w\right)$ units of time in them. One's minimum exercise requirement is increased by work-related stress, but may be reduced by time spent in spiritual pursuits, such as prayer (Powell, et al., 2003). However, for some, time spent in spiritual activities could be deleterious to their health. This could be the case for one in conflict with the tenets of their faith or having a crisis of faith. For others, such as agnostics, there is no value, either direct or indirect, of spiritual activities. For analytical simplicity we assume that $\hat{e}\left(t^{s}, w\right)$ is a linear function of $t^{s}$ and $w$, that is,

$$
\hat{e}\left(t^{s}, w\right)=\sigma^{w} w-\sigma^{s} t^{s}, \quad \sigma^{w} \in[0,1] .
$$

The benefit one gets per unit of medical care, $\mu(\rho)$, or per unit of healthy activity, $\chi(\rho)$, depends on one's ability to cope with stress, to make sense of a complex universe. This, in turn, may

\footnotetext{
${ }^{16}$ We have modeled consumption and leisure using this Stone-Geary like utility function specifically to emphasize that there are things that we must do before we can do what we want to do. At the most basic level, these must do's ensure survival. However, modern society imposes imperatives, actual or perceived, that must be fulfilled before the individual can attend to improving his personal well-being (see de Graaf 2003, Hochschild, 1997, and Schor, 1992). This modeling choice can be further justified by Blanchflower and Oswald's (2004) finding that relative income (status) rather than absolute income matters. We introduce relative, or social norm effects, via the $\xi$ and $\lambda$ parameters.
} 
depend on one's religious practice or place in a faith community. ${ }^{17}$ We liken this, as mentioned above, to Antonovsky's sense of coherence (SOC), or the spiritual capital one has accumulated in one's community. ${ }^{18}$ Spiritual capital or sense of coherence (or what gives you a sense of coherence) depend on, among other things, the resources controlled by one's religious community, time spent in communal interaction, and the spiritual guidance provided, institutional strength, moral authority, doctrinal consistency, stability, etc., of one's Church. We capture these effects in the index $\rho$.

To complete our model, we note that the individual has a single unit of time to allocate

$$
1=t^{\ell}+t^{s}+e+w
$$

a portion, $w$, of which goes to work, the remaining time being divided among leisure, $t^{\ell}$, healthy activities, $e$, and spiritual pursuits, $t^{s}$.

Individuals divide their income, $w I$, between consumption goods, $c$ (priced at $p^{c}$ ), health enhancing medical goods, $m$ (priced at $p^{m}$ ), and spiritual expenditures, such as donations, tithes, etc., $s$. Since the effect of these on one's spirituality are defined relative to income,

$$
\bar{s}=\frac{w I-p^{c} c-p^{m} m}{w I} \quad \text { where } \quad w I=p^{c} c+p^{m} m+s
$$

\footnotetext{
${ }^{17}$ Members of religious communities, such as the Trappists and Benedictines, have been shown to have lower mortality risk than the general population (de Gouw, et al., 1995). Further, empirical studies show that communal aspects of religious observance are critical to one's health and longevity. See for example, Powell, et al. (2003). Yet, as Kark, et al. (1996) show, community without religion is not enough.

${ }^{18}$ Alternatively, we can interpret our well-being function as a utility function defined over own actions, other's actions, and one's identity, as described in Akerlof and Kranton (2000). In this interpretation one's identity depends on one's religiosity which is one's assigned or chosen social category, the $g$ 's are one's own characteristics relative to the ideal for one's category, and the $\mu, \gamma, \lambda$, and $\xi$ parameters measure the benefit to that identity (the benefit of being a member of a religious community), and so summarize the effects of other's actions upon you.
} 
Our modeling choices allow us to define the three types of individuals enumerated above.

Agnostics' beliefs are parameterized by $g_{1}=g_{2}=\sigma^{s} \equiv 0$ so that $\chi\left(t^{s}, \bar{s}\right)=1$ and $\xi$ and $\lambda$ are positive constants: health and well-being are not affected by spirituality. Spiritual nonreligious individuals' beliefs are parameterized by assuming $g_{1}>0, g_{2}=0$, and $\sigma^{s}>0$ so that $\chi\left(t^{s}, \bar{s}\right)=\left(t^{s}+a_{1}\right)^{g_{1}}$ suggesting that spiritual rewards are not confined to those who are members of faith communities. Faith community members' beliefs are parameterized by assuming $g_{1}>0$, $g_{2}>0$ and $\sigma^{s}>0$ so that $\chi\left(t^{s}, \bar{s}\right)=\left(t^{s}+a_{1}\right)^{g_{1}}\left(\bar{s}+a_{2}\right)^{g_{2}}$, suggesting that spirituality is linked to religious practice in an ecclesial context. For both agnostics and the spiritual nonreligious, religious community (SOC) effects that work through the $g, \mu$ and $\gamma$ parameters are absent. This is not to suggest that they do not benefit from their memberships (social capital) in nonreligious groups, but the additional benefit from membership in a faith community is absent. ${ }^{19}$

In this analysis we are interested in determining how individuals allocate their resources taking their place in the world as given. In a companion piece we will examine the formation of community and thus look into the source of these benefits.

\section{Caring for the Body, Mind and Spirit}

Individuals must choose how to allocate their time and their money among the various uses to maximize their well-being. To solve the individual's maximization problem substitute Equations (2) through (7) into Equation (1) to yield

\footnotetext{
${ }^{19}$ See Putnam (2000) for a comparison of the health/happiness benefits of different types of social capital.
} 


$$
\begin{gathered}
W=\left(a_{1}+t^{s}\right)^{g_{1}}\left(a_{2}+\frac{w I-p^{c} c-p^{m} m}{w I}\right)^{g_{2}}\left(c-\xi\left(g_{1}\right)\right)^{\alpha}\left(1-t^{s}-e-w-\lambda\left(g_{1}\right)\right)^{\beta} \times \\
\left(h_{0}+\mu(\rho) m+\gamma(\rho)\left(e-\sigma^{w} w+\sigma^{s} t^{s}\right)\right)^{v} .
\end{gathered}
$$

Maximize (8) with respect to $t^{s}, c, m$, and $e$. The first-order conditions of the individual's problem with respect to $t^{s}, c, m$, and $e$, respectively, are, after some simplification

$$
\begin{aligned}
& g_{1}\left(t^{\ell}-\lambda\left(g_{1}\right)\right) h=\left(a_{1}+t^{s}\right)\left[\beta h-\gamma(\rho) v \sigma^{s}\left(t^{\ell}-\lambda\left(g_{1}\right)\right)\right] \\
& \frac{p^{c} g_{2}}{w I}\left(c-\xi\left(g_{1}\right)\right)=\alpha\left(a_{2}+\bar{s}\right) \\
& \frac{p^{m} g_{2}}{w I} h=\mu(\rho) v\left(a_{2}+\bar{s}\right) \\
& \beta h=\gamma(\rho) v\left(t^{\ell}-\lambda\left(g_{1}\right)\right) .
\end{aligned}
$$

The individual equates the marginal benefit of time spent in spiritual pursuits to the marginal cost of leisure foregone, Equation (9). Notice, the marginal benefit of this time has two components since it provides direct benefits in terms of spiritual well-being, and indirect benefits in terms of physical and mental health. In Equation (10) he equates the marginal benefit of consumption to its marginal costs in terms of spiritual expenditures foregone, while in Equation (11) he equates the marginal benefit of expenditures on medical care with the marginal cost of spiritual expenditures foregone. Finally, in Equation (12) he equates the marginal benefit of time spent in healthy pursuits to the marginal cost of leisure foregone.

Equations (9) through (12) can be reduced to a single equation in a single unknown. These algebraic derivations can be found in Appendix 1. The equations defining the endogenous 
variables can then be totally differentiated to yield the following results. These derivations are found in Appendix 2.

Since we are interested in the effects of religion and spirituality on health, we concentrate our analysis on the behavior of members of faith communities, noting where relevant, how the spiritual nonreligious and agnostics differ in their behavior.

Proposition 1: Whenever one's spirituality does not serve to isolate one from certain (perceived or actual) social pressures associated with consumption and time, physical and mental health, as defined conventionally, are decreasing, whereas medical expenditures are increasing in one's spirituality. That is,

$$
\frac{d \xi}{d g_{1}}=\frac{d \lambda}{d g_{1}}=0 \Rightarrow \frac{d h}{d g_{1}}<0 \text { and } \frac{d m}{d g_{1}}>0
$$

Moreover, physical and mental health as well as medical expenditures are decreasing in one's altruism. That is,

$$
\frac{d h}{d g_{2}}<0 \text { and } \frac{d m}{d g_{2}}<0
$$

The effects of spirituality on health are complex and work through a number of distinct channels. It is important, however, to note that while those who are the most altruistic and have the greatest spiritual openness, those most receptive among us, may not also be the healthiest, ${ }^{20}$ they do have greater subjective well-being than their less altruistic and spiritual peers. These results are consistent with Ferriss (2002) and Ellison (1991) who both show that the more religious, spiritual and altruistic by our definition, are also happier. But, if we exclude the possibility that greater

\footnotetext{
${ }^{20}$ It is, perhaps, theologically misleading to say that there are some who more spiritual than others, rather, there are those who are more receptive to the overture of God, the Word of God in its broadest sense. This is at the heart of the theology of grace as was classically explored by Augustine in his Confessions.
} 
spirituality reduces one's susceptibility to social pressures, then the more spiritual will be less healthy, as conventionally defined, ${ }^{21}$ and they will spend more on traditional medical care than their less spiritual peers. Greater altruism unambiguously reduces health and medical care expenditure - in caring for others one cares less for oneself.

These results contradict an extensive body of empirical research, suggesting that the effects of spirituality on health work through additional channels, such as reducing one's susceptibility to social pressures.

Proposition 2: Physical and mental health, as conventionally defined, may increase and medical expenditures may decrease with the level of spirituality, provided that greater spirituality reduces one's susceptibility to social pressures. That is,

$$
\frac{d h}{d g_{1}}>0 \text { and } \frac{d m}{d g_{1}}<0 \Rightarrow \frac{d \xi}{d g_{1}}<0 \text { and } \frac{d \lambda}{d g_{1}}<0
$$

Moreover, if the institutional strength of one's religious community enhances one's spirituality, the more time and money (under minor restrictions) one is willing to provide to the Church, and unequivocally the greater is one's well-being. That is, if $g_{1}(\rho), g_{1}{ }^{\prime}>0$ then

$$
\begin{aligned}
& \text { I large, } \gamma^{\prime} \text { and } 1-\sigma^{s} \text { small } \Rightarrow \frac{\partial t^{s}}{\partial \rho}>0 \text { and } \frac{\partial \bar{s}}{\partial \rho}>0 . \\
& \frac{d W}{d \rho}>0
\end{aligned}
$$

When greater spirituality increases one's resistance to social pressures, both income and time are freed up for other, perhaps health enhancing, uses. If the time effect dominates the income effect, then medical expenditures fall while health rises. But, should there be a crisis in one's Church (a reduction of $\rho$ ) such as the pedophilia scandal in the Catholic Church or the threat of schism in

\footnotetext{
${ }^{21}$ On this distinction see, e.g., Jacobs (2001).
} 
the Anglican Communion as a result of Gene Robinson's election as Bishop, then the moral authority of the Church may be undermined which has an impact upon the Church's ability to act as a spiritual guide. The subjective well-being of community members falls, as do time and money devoted to the community (Post, 2003; Economist, 2005). Yet, faith communities often survive as their members can see beyond the failings of their leaders as, indeed, they are instructed to do (Matt 23:2-3).

Proposition 3: The greater one's spiritual capital, that is, the stronger one's sense of coherence, the better is one's health, the lower (under minor restrictions) are one's medical expenditures, and the higher is one's subjective well-being.

$$
\begin{aligned}
& \frac{d h}{d \mu}, \frac{d h}{d \gamma}, \frac{d W}{d \mu}, \frac{d W}{d \gamma}>0 \\
& \frac{d m}{d \gamma}<0 \text { and, for large } I, \frac{d m}{d \mu}<0 .
\end{aligned}
$$

The more religious have repeatedly been shown to be healthier, as conventionally defined. This health benefit of spirituality may work through a community channel via one's spiritual capital or sense of coherence. Thus, if we compare two individuals who are identical except one has a stronger SOC or more spiritual capital, a more secure place in the community or the implicit or explicit support of the community (George, et al., 2000; Powell, et al, 2003), or stronger faith (Ellison, 1991; DeVido, 2003; Goldhaber, 2003), that is, higher $\mu$ or higher $\gamma$, then the former will be healthier, both broadly and narrowly defined. Further, those with higher $\gamma$, those less susceptible to the slings and arrows of everyday life, will also spend less on medical care and less time in purely healthy activities, opting instead for more spiritual activities, while still enjoying better health. These are the healthy individuals to whom Koenig, et al., (2001, p. 4) refer, the devout in religious belief and practice, who will be both more resistant to health problems and respond more positively to treatments, and so will be less likely to require expensive 
interventions to cure them. To the extent that this spiritual capital or sense of coherence is a function of one's communal religious practice, and distinct from social capital resulting from membership and participation in nonreligious groups and activities, then neither the spiritual but nonreligious, nor agnostics can avail themselves of it.

Proposition 4: An increase in the price of medical care reduces spiritual time and can reduce donations. Therefore, it has a negative spillover effect on spiritual capital parameters leading to reductions in one's health and well-being.

$$
\frac{d h}{d p^{m}}, \frac{d t^{s}}{d p^{m}}, \frac{d W}{d p^{m}}<0 \text { and } \frac{d \bar{s}}{d p^{m}}<0 \text { if I large. }
$$

The increase in the cost of medical care causes individuals to substitute away from the relatively more expensive medical care into the relatively cheaper consumption goods and spiritual expenditures. Since real income is now lower, demand for all goods is reduced: spiritual expenditures fall and less health care is purchased. Time is reallocated away from spiritual pursuits into physically healthy activities to offset the loss. But, as a result of higher health care costs, individuals are less healthy both broadly (subjective well-being) and narrowly (mental and physical health) defined.

More expensive health care also extracts resources from religious communities both in terms of time and money. Since the resources controlled by the community as well as time spent interacting with one's fellow community members fall, one's spiritual capital and one's sense of coherence will be adversely affected, reducing $\gamma$ and $\mu$, further compromising individuals' health. Thus, when religious communities are called upon to fill the breach, as they have in some instances, e.g., in response to the 1996 Welfare Reform legislation (Hungerman 2004), they cannot heed this call. 


\section{Is There a Role for Public Policy?}

Clearly, to the extent that health policy can control and reduce health care costs, reduce $p^{m}$, everyone will be made better off. However, we are currently in an era of rising costs with no respite foreseen. If it is the case that as costs rise so does the effectiveness of healthcare expenditures, then there would not be a problem. However, if more is being paid for the same quality of care a concern remains. For policy to effect better outcomes it must affect one's ability to produce health, that is to increase $\gamma$ and $\mu$, or affect the sociological constraints on one's income and time, reduce $\xi$ and $\lambda$. To the extent that $\xi$ and $\lambda$ are determined by an individual's spirituality, and $\gamma$ and $\mu$ are determined by the strength of one's spiritual capital in or sense of coherence from membership in a religious (rather than nonreligious) community, the policies must be pastoral rather than secular. Can a secular state, which benefits from the healthiness and low medical care usage of religious individuals, play a positive role without crossing the State Church divide?

Public policies designed to increase the positive external effect of religion on health would have to facilitate rather than mandate religious practice. The State can make it easier for religious organizations to operate via their tax exempt status, or increase the benefit to giving via the tax deductibility of contributions to charitable organizations. It can facilitate religious observance by restricting work hours or commerce on Sabbaths and holy days. The State can subsidize pastoral care, which has been shown to have positive health benefits. For example, in some Irish Staterun Schools (e.g., Community Schools), as well as in Irish Universities, financial provision is made for the payment of chaplains. The health benefits are compelling, as also are the educational benefits, in that more students complete their programs of study more effectively, with obvious net fiscal savings for the State. The State can, also, create an atmosphere of 
religious tolerance and respect through legal protections such as the establishment and free exercise clauses of the Constitution of the United States.

But public policy can, intentionally or not, have mitigating or negative effects. For example, state funding for and staffing of religious organizations (as is found in many European countries) can crowd out individual donations of both money and time, reducing the communal benefits of religious practice, as suggested by Iannaccone, et al. (1997) and Stark and Finke (2000). Further, state funding, and the requirements of that funding, can call into question the professed goal and beliefs of the religious organizations. If accepting funding means compromising on beliefs, which master is being served, God or Mammon? If the latter, which community is being served and whose work is being done $?^{22}$ Further, if the state is not seen as a force for good or as a moral authority, an explicit Church - State link can reduce the moral authority of the Church (Moeller, 2004), thus depreciating the value of members' spiritual capital. While the State can provide information about religions, such as in state sponsored school religious education, this could lead individuals to religious practice, or drive them away. ${ }^{23}$ The State can make religious observance more difficult via various planning, land use, and public property restrictions. It can also restrict observance by prohibiting religious practice such as banning headscarves in public schools. Finally, the State can create an atmosphere, legal or political, in which the survival of Churches and other religious communities as independent entities is challenged. This overt persecution may undermine, but can ultimately strengthen these communities.

\footnotetext{
${ }^{22}$ Indirect evidence of this is found in the link between religiosity and volunteering, both for church related and generally. In the United States where there is a strict separation of church and state, the more religious volunteer more (Greeley, 1997). In Finland, where there is a national, state-funded church, church-based volunteerism among the members of the national church with its large well-paid staff is much lower than church-based volunteerism among members of other religions (Yeung, 2004). Thus, "the potential for social capital formation within the church is diffused, diminished, or perhaps never even formed." (Yeung, 2004, p.415)

${ }^{23}$ In the United States where religious education is provided by the church not the state, as average education levels have increased membership in church groups has fallen (Helliwell and Putnam, 1999). The same trend was observed in Ireland in the 1970s and 1980s: the initial drift away from regular Church practice was observed in educated urban settings, and among young men more than among young women.
} 


\section{Conclusion}

We present a model of choice in which an individual divides his time between work, leisure, healthy activities and spiritual activities, and divides his income between consumption goods, medical care, and gifts/donations to his Church. The competing demands on the individual's time and money so central to modern life are made explicit. The individual balances the costs and benefits of the various uses of his time and his money to maximize his well-being.

We find that the subjective well-being of the more spiritual will be higher, but they may not be healthier than their peers, while those whose faith and whose membership in a faith community provides a superior ability to cope with stress and illness will have both higher levels of health and subjective well-being. To the extent that religious faith allows one to withstand the uncompensated pressures and demands of society, one will also have higher levels of health and subjective well-being.

These positive health effects and their external benefits in terms of lower health care needs and usage are, unfortunately, not directly amenable to exploitation by public policy. Yet, while faith and religious devotion cannot be mandated by the State, they can be facilitated by it. It is necessary, therefore, for Churches and religious communities clearly to articulate the nature and worth of their missions. They must explain to the State how their missions may be facilitated without compromising their beliefs or abandoning their communities for benefits to continue to accrue to the State. But, Churches must realize that, fundamentally, it is they who provide the faithful with resources for living, with a sense of coherence via the religious beliefs they espouse. To the extent that they do not connect with, or meet the expectations of, or fulfill the spiritual needs of their members, they will find their congregations shrinking and no amount of government money will stem the outflow or offset the reductions in health - spiritual, physical or mental. 


\section{Appendix 1}

For convenience, we rewrite the model in full. Let preferences be defined by the following function

Let an individual's well-being be defined by the composite function

$$
\chi\left(t^{s}, \bar{s}\right) U\left(c, t^{\ell}, h\right)
$$

where

$$
\begin{gathered}
\chi\left(t^{s}, \bar{s}\right)=\left(a_{1}+t^{s}\right)^{g_{1}}\left(a_{2}+\bar{s}\right)^{g_{2}}, \quad g_{1} \geq 0, g_{2} \geq 0, a_{1} \geq 1, a_{2} \geq 1, \\
U\left(c, t^{\ell}, h\right)=\left(c-\xi\left(g_{1}\right)\right)^{\alpha}\left(t^{\ell}-\lambda\left(g_{1}\right)\right)^{\beta} h^{v} \\
\alpha+\beta+v \leq 1,0<\alpha, \beta, v<1, \xi(0)>0, \xi^{\prime} \leq 0, \lambda(0)>0, \lambda^{\prime} \leq 0, \\
h=h_{0}+\mu(\rho) m+\gamma(\rho)\left(e-\hat{e}\left(t^{s}, w\right)\right), \\
h_{0} \geq 0, \mu(0)>0, \mu^{\prime}>0 ; \gamma(0)>0, \gamma^{\prime}>0 . \\
\hat{e}\left(t^{s}, w\right)=\sigma^{w} w-\sigma^{s} t^{s}, \sigma^{w} \in[0,1] . \\
\begin{array}{c}
1=t^{\ell}+t^{s}+e+w \\
\bar{s}=\frac{w I-p^{c} c-p^{m} m}{w I} \quad w I=p^{c} c+p^{m} m+s
\end{array}
\end{gathered}
$$


The individual agent chooses $t^{s}, c, m$, and $e$ to maximize

$$
\begin{gathered}
W=\left(a_{1}+t^{s}\right)^{g_{1}}\left(a_{2}+\frac{w I-p^{c} c-p^{m} m}{w I}\right)^{g_{2}}\left(c-\xi\left(g_{1}\right)\right)^{\alpha}\left(1-t^{s}-e-w-\lambda\left(g_{1}\right)\right)^{\beta} \times \\
\left(h_{0}+\mu(\rho) m+\gamma(\rho)\left(e-\sigma^{w} w+\sigma^{s} t^{s}\right)\right)^{v} .
\end{gathered}
$$

which defines the individual's subjective well-being. The first-order conditions of the individual's problem with respect to $t^{s}, c, m$, and $e$, respectively, are,

$$
\begin{aligned}
& -\frac{p^{c} g_{2}}{w I}\left(c-\xi\left(g_{1}\right)\right)+\alpha\left(a_{2}+\bar{s}\right)=0 \\
& g_{1}\left(t^{\ell}-\lambda\left(g_{1}\right)\right) h-\left(a_{1}+t^{s}\right)\left[\beta h-\gamma(\rho) v \sigma^{s}\left(t^{\ell}-\lambda\left(g_{1}\right)\right)\right]=0 \\
& -\frac{p^{m} g_{2}}{w I} h+\mu(\rho) v\left(a_{2}+\bar{s}\right)=0 \\
& -\beta h+\gamma(\rho) v\left(t^{\ell}-\lambda\left(g_{1}\right)\right)=0 .
\end{aligned}
$$

Combine equations (9) and (12) to derive the definition of $t^{s}$

$$
t^{s}=\frac{g_{1}}{g_{1}+\beta\left(1-\sigma^{s}\right)}\left(1-e-w-\lambda\left(g_{1}\right)\right)-\frac{\beta a_{1}\left(1-\sigma^{s}\right)}{g_{1}+\beta\left(1-\sigma^{s}\right)} .
$$

Combine equations (13) and (6) to derive the definition of $t^{\ell}$

$$
t^{\ell}=\frac{\beta\left(1-\sigma^{s}\right)}{g_{1}+\beta\left(1-\sigma^{s}\right)}(1-e-w)+\frac{g_{1} \lambda\left(g_{1}\right)+\beta a_{1}\left(1-\sigma^{s}\right)}{g_{1}+\beta\left(1-\sigma^{s}\right)} .
$$

Combine (11), (12), and (14) to yield 


$$
m=\frac{w I\left(1+a_{2}\right)-p^{c} c}{p^{m}}-\frac{g_{2} \gamma\left(1-\sigma^{s}\right)\left[1-e-w-\lambda\left(g_{1}\right)+a_{1}\right]}{\mu\left[g_{1}+\beta\left(1-\sigma^{s}\right)\right]} .
$$

Combine (10) and (11) to derive the definition of $c$,

$$
c=\frac{p^{m}}{p^{c}} \frac{\alpha \gamma}{\mu} \frac{\left(1-\sigma^{s}\right)}{g_{1}+\beta\left(1-\sigma^{s}\right)}\left[1-e-w-\lambda\left(g_{1}\right)+a_{1}\right]+\xi\left(g_{1}\right)
$$

Combine (15) and (16) to define $m$

$$
m=\frac{w I\left(1+a_{2}\right)-p^{c} \xi\left(g_{1}\right)}{p^{m}}-\frac{\gamma\left(1-\sigma^{s}\right)\left(\alpha+g_{2}\right)\left[1-e-w-\lambda\left(g_{1}\right)+a_{1}\right]}{\mu\left[g_{1}+\beta\left(1-\sigma^{s}\right)\right]} .
$$

Combine (4), (5), (13), and (17) to derive the definition of $h$

$$
\begin{aligned}
h= & h_{0}+\mu\left[\frac{w I\left(1+a_{2}\right)-p^{c} \xi\left(g_{1}\right)}{p^{m}}\right]+\gamma\left(e-\sigma^{w} w\right)+ \\
& \frac{\left(1-e-w-\lambda\left(g_{1}\right)\right) \gamma\left[g_{1} \sigma^{s}-\left(\alpha+g_{2}\right)\left(1-\sigma^{s}\right)\right]}{g_{1}+\beta\left(1-\sigma^{s}\right)}-\frac{\gamma a_{1}\left(1-\sigma^{s}\right)\left[\left(\alpha+g_{2}\right)+\sigma^{s} \beta\right]}{g_{1}+\beta\left(1-\sigma^{s}\right)}
\end{aligned}
$$

Combine (7), (16) and (17) to define $\bar{s}$

$$
\bar{s}=\frac{p^{m} g_{2} \gamma\left(1-\sigma^{s}\right)\left(1-e-w-\lambda\left(g_{1}\right)+a_{1}\right)}{\mu w I\left[g_{1}+\beta\left(1-\sigma^{s}\right)\right]}-a_{2},
$$

Finally, combine (12), (14) and (18) to implicitly define $e$

$$
\begin{aligned}
-h_{0}-\mu\left[\frac{w I\left(1+a_{2}\right)-p^{c} \xi\left(g_{1}\right)}{p^{m}}\right]-\gamma\left(e-\sigma^{w} w\right) & \\
- & \frac{\left(1-e-w-\lambda\left(g_{1}\right)\right) \gamma\left[g_{1} \sigma^{s}-\left(g_{2}+\alpha+v\right)\left(1-\sigma^{s}\right)\right]}{g_{1}+\beta\left(1-\sigma^{s}\right)} \\
& +\frac{\left(1-\sigma^{s}\right) \gamma a_{1}\left[\left(g_{2}+\alpha+v\right)+\sigma^{s} \beta\right]}{g_{1}+\beta\left(1-\sigma^{s}\right)}=0 .
\end{aligned}
$$




\section{Appendix 2}

Total differentiation of equation (19) and the various definitions of the endogenous variables yields the following results under the following assumptions on parameter values:

A1. $1>\sigma^{s}$. If not, time spent in healthy activities, $e$, would be zero. We abstract from this case.

A2. $e-\sigma^{w} w>0$. Minimum exercise demands are not excessive.

Proof of Proposition 1:

(i) $\frac{d h}{d g_{1}}=-v\left[\frac{\gamma\left(1-\sigma^{s}\right)\left(1-e-w-\lambda+a_{1}\right)}{\left[g_{1}+\beta\left(1-\sigma^{s}\right)\right]}\right]\left[\frac{1}{g_{1}+g_{2}+\alpha+\beta+v}\right]<0$

$$
\frac{d m}{d g_{1}}=\left[\frac{\gamma\left(\alpha+g_{2}\right)\left(1-\sigma^{s}\right)\left(1-e-w-\lambda+a_{1}\right)}{\mu\left[g_{1}+\beta\left(1-\sigma^{s}\right)\right]\left[g_{1}+g_{2}+\alpha+\beta+v\right]}\right]>0
$$

(ii) $\frac{d h}{d g_{2}}=-v\left[\frac{\gamma\left(1-\sigma^{s}\right)\left(1-e-w-\lambda+a_{1}\right)}{\left[g_{1}+\beta\left(1-\sigma^{s}\right)\right]}\right]\left[\frac{1}{g_{1}+g_{2}+\alpha+\beta+v}\right]<0$

$$
\frac{d m}{d g_{2}}=-\left[\frac{\gamma\left(1-\sigma^{s}\right)\left(1-e-w-\lambda+a_{1}\right)}{\mu\left[g_{1}+\beta\left(1-\sigma^{s}\right)\right]}\right]\left[\frac{g_{1}+\beta+v}{g_{1}+g_{2}+\alpha+\beta+v}\right]<0 .
$$


Proof of Proposition 2:

(i)

$$
\begin{aligned}
& \frac{d h}{d g_{1}}=-\left[\frac{v}{g_{1}+g_{2}+\alpha+\beta+v}\right]\left\{\left[\frac{\gamma\left(1-\sigma^{s}\right)\left(1-e-w-\lambda+a_{1}\right)}{\left[g_{1}+\beta\left(1-\sigma^{s}\right)\right]}\right]+\frac{\mu p^{c}}{p^{m}} \xi^{\prime}+\gamma \lambda^{\prime}\right\}>0 \\
& \text { if }\left[\frac{\gamma\left(1-\sigma^{s}\right)\left(1-e-w-\lambda+a_{1}\right)}{\left[g_{1}+\beta\left(1-\sigma^{s}\right)\right]}\right]<-\frac{\mu p^{c}}{p^{m}} \xi^{\prime}-\gamma \lambda^{\prime} \\
& \begin{array}{c}
\frac{d m}{d g_{1}}=\left[\frac{\gamma\left(\alpha+g_{2}\right)}{\mu\left[g_{1}+\beta\left(1-\sigma^{s}\right)\right]\left[g_{1}+g_{2}+\alpha+\beta+v\right]}\right] \times \\
-\left[\frac{g_{1}+\beta+v}{g_{1}+g_{2}+\alpha+\beta+v} \frac{p^{c}}{p^{m}} \xi^{\prime}\right]<0
\end{array}
\end{aligned}
$$

if $\xi^{\prime}$ and $1-\sigma^{s}$ small.

(ii) Under the assumption that $g_{1}=g_{1}(\rho), g_{1}{ }^{\prime}>0$

$$
\frac{\partial t^{s}}{\partial \rho}=\left\{\begin{array}{l}
\frac{\left(1-e-w-\lambda+a_{1}\right) \beta\left(1-\sigma^{s}\right)}{\left[g_{1}+\beta\left(1-\sigma^{s}\right)\right]} g_{1}^{\prime}\left[\frac{g_{2}+\alpha+\beta+v}{g_{1}+g_{2}+\alpha+\beta+v}\right]- \\
\frac{\mu p^{c} \xi^{\prime} g_{1}^{\prime}}{p^{m}} \frac{1}{\gamma\left(1-\sigma^{s}\right)\left[g_{1}+g_{2}+\alpha+\beta+v\right]}+ \\
\frac{\gamma^{\prime} g_{1}\left[\begin{array}{l}
\left(e-\sigma^{w} w\right)\left[g_{1}+\beta\left(1-\sigma^{s}\right)\right]+ \\
(1-e-w-\lambda)\left[g_{1} \sigma^{s}-\left(g_{2}+v+\alpha\right)\left(1-\sigma^{s}\right)\right]-a_{1}\left(g_{2}+\alpha+v+\sigma^{s} \beta\right)\left(1-\sigma^{s}\right)
\end{array}\right]}{\gamma\left(1-\sigma^{s}\right)\left[g_{1}+g_{2}+\alpha+\beta+v\right]} \\
-\frac{\mu^{\prime} g_{1}\left[w I\left(1+a_{2}\right)-p^{c} \xi\right]}{\left(1-\sigma^{\prime}\right)\left[g_{1}+g_{2}+\alpha+\beta+v\right]}+\frac{p^{m} \gamma\left(1-\sigma^{s}\right)\left[g_{1}+g_{2}+\alpha+\beta+v\right]}{p^{m} \gamma}
\end{array}\right]>0
$$

and 


$$
\begin{aligned}
& \frac{\partial \bar{s}}{\partial \rho}=\frac{p^{m} g_{2}}{\mu w I}\left[\frac{1}{\left(g_{1}+g_{2}+\alpha+\beta+v\right)}\right] \times \\
& {\left[\begin{array}{l}
-\frac{\mu p^{c} \xi^{\prime} g_{1}{ }^{\prime}}{p^{m}}-\gamma \lambda^{\prime} g_{1}{ }^{\prime}-\frac{\left(1-\sigma^{s}\right) \gamma g_{1}{ }^{\prime}}{g_{1}+\beta\left(1-\sigma^{s}\right)} \\
\mu^{\prime}\left\{\left[\frac{w I\left(1+a_{2}\right)-p^{c} \xi}{p^{m}}\right]-\left(1-e-w-\lambda+a_{1}\right) \frac{\gamma\left(1-\sigma^{s}\right)\left(g_{1}+g_{2}+\alpha+\beta+v\right)}{g_{1}+\beta\left(1-\sigma^{s}\right)}\right\}+ \\
\gamma^{\prime}\left[e-\sigma^{w} w+\left(1-e-w-\lambda+a_{1}\right)\right]
\end{array}\right]>0}
\end{aligned}
$$

for $I$ large, $\gamma^{\prime}$ and $1-\sigma^{s}$ small.

$$
\frac{d W}{d \rho}=\ln \left(t^{s}+a_{1}\right) W-\frac{\alpha \xi^{\prime} W}{(c-\xi)}-\frac{\beta \lambda^{\prime} W}{\left(t^{\ell}-\lambda\right)}+\ln \left(\bar{s}+a_{2}\right) W>0 .
$$

\section{Proof of Proposition 3:}

$$
\begin{aligned}
& \frac{d h}{d \mu}=v \frac{\left[w I\left(1+a_{2}\right)-p^{c} \xi\right]}{p^{m}\left[g_{1}+g_{2}+\alpha+\beta+v\right]}>0 \\
& \frac{d h}{d \gamma}=v\left[\frac{\left.e-\sigma^{w} w+\left(1-e-w-\lambda+a_{1}\right)-a_{1} \sigma^{s}\right]}{g_{1}+g_{2}+\alpha+\beta+v}\right]>0 \\
& \frac{d m}{d \mu}=\frac{\gamma\left(1-\sigma^{s}\right)\left(\alpha+g_{2}\right)}{g_{1}+\beta\left(1-\sigma^{s}\right)}\left[\frac{1-e-w-\lambda+a_{1}}{\mu^{2}}-\frac{\left[w I\left(1+a_{2}\right)-p^{c} \xi\right]\left[g_{1}+\beta\left(1-\sigma^{s}\right)\right]}{\mu p^{m}\left(1-\sigma^{s}\right)\left(g_{1}+g_{2}+\alpha+\beta+v\right)}\right]<0
\end{aligned}
$$

for large $I$.

$$
\begin{aligned}
& \frac{d m}{d \gamma}=-\frac{\alpha+g_{2}}{\mu\left[g_{1}+g_{2}+\alpha+\beta+v\right]}\left[\left(1-e-w-\lambda+a_{1}\right)-a_{1} \sigma^{s}+\left(e-\sigma^{w} w\right)\right]<0 \\
& \frac{d W}{d \mu}=\frac{v W m}{h}>0
\end{aligned}
$$


$\frac{d W}{d \gamma}=\frac{\nu W}{h}\left(e-\sigma^{w} w+\sigma^{s} t^{s}\right)>0$.

Proof of Proposition 4:

$$
\begin{aligned}
\frac{d h}{d p^{m}} & =-\frac{\mu \nu\left[w I\left(1+a_{2}\right)-p^{c} \xi\right]}{\left(p^{m}\right)^{2}\left[g_{1}+g_{2}+\alpha+\beta+v\right]}<0 \\
\frac{d W}{d p^{m}} & =-\frac{g_{2} m W}{w I\left(\bar{s}+a_{2}\right)}<0 \\
\frac{d t^{s}}{d p^{m}} & =-\frac{\mu g_{1}\left[w I\left(1+a_{2}\right)-p^{c} \xi\right]}{\left(p^{m}\right)^{2} \gamma\left(1-\sigma^{s}\right)\left[g_{1}+g_{2}+\alpha+\beta+v\right]}<0 \\
\frac{d \bar{s}}{d p^{m}} & =-\frac{\gamma\left(1-\sigma^{s}\right) g_{2}}{w I\left[g_{1}+\beta\left(1-\sigma^{s}\right)\right]}\left[\frac{\left[w I\left(1+a_{2}\right)-p^{c} \xi\right]\left[g_{1}+\beta\left(1-\sigma^{s}\right)\right]}{p^{m} \gamma\left(1-\sigma^{s}\right)\left(g_{1}+g_{2}+\alpha+\beta+v\right)}-\frac{1-e-w-\lambda+a_{1}}{\mu}\right]<0
\end{aligned}
$$

for large $I$. 


\section{References}

Akerlof, G.A., and Kranton, R.E., 2000, “Economics and Identity," Quarterly Journal of Economics 115, 715-753.

Anonymous, 1996, The Cloud of Unknowing, W. Johnston, ed., Garden City, NY: Image Books.

Antonovsky, A., 1979, Health, Stress, and Coping: New Perspectives on Mental and Physical Well-Being. San Francisco: Jossey-Bass.

Antonovsky, A., 1987, Unraveling the Mystery of Health: How People Manage Stress and Stay Well, San Francisco: Jossey-Bass.

Bednarek, H.L., Pecchenino, R.A., and Stearns, S.C., 2005, "Health Choices and Health Outcomes: Does Healthier Mean Happier?" Michigan State University Department of Economics Working Paper.

Bednarek, H.L., Jeitschko, T.D., and Pecchenino, R.A., 2004, "Gluttony and Sloth: Symptoms of Trouble or Signs of Bliss?" Michigan State University Department of Economics Working Paper.

Blanchflower, D.G., and Oswald, A.J., 2004, "Well-Being over Time in Britain and the USA," Journal of Public Economics 88, 1359-86.

Cohen, A.B., 2002, "The Importance of Spirituality in Well-Being for Jews and Christians," Journal of Happiness Studies 3, 287-310.

De Gouw, H.W.F.M., Westendorp, R.G.J., Kunst, A.E., Mackenbach, J.P., and Vandenbroucke, J.P., 1995, "Decreased Mortality among Contemplative Monks in the Netherlands," American Journal of Epidemiology 141, 771-75.

De Graff, J., ed, 2003 Take Back Your Time: Fighting Overwork and Time Poverty in America. San Francisco: Berrett-Koehler.

DeVido, J., 2003, "Contemplative Continuity: Conceptions of Health and Illness in a Trappist Abbey," in Religious Healing in Boston: Reports from the Field, S. Saved, ed., Boston: Center for the Study of World Religions.

Driscoll, J.J., 2002, “And the Nominees Are...Spiritual Care, Pastoral Care,” Vision 12.

Driscoll, J.J., 2003, "HIPPA Calling the Question: Is the Chaplain a Health Care Professional?" Vision 13.

Economist, 2005, "Episcopalians at Sea: God Help Them," 19 February, p. 30.

Ellison, C.G., 1991, "Religious Involvement and Subjective Well-Being," Journal of Health and Social Behavior, 32, 80-99.

Ferriss, A.L., 2002, "Religion and the Quality of Life," Journal of Happiness Studies 3, 199-215. 
Freud, S., 1907 (1962), Obsessive Acts and Religious Practices, in J. Strachey, ed. and trans., Standard Edition of the Complete Psychological Works of Sigmund Freud. London: Hogarth Press.

Fukuyama, F., 2000, "Social Capital and Civil Society," International Monetary Fund Working Paper 00/74.

George, L.K., Larson, D.B., Koenig, H.G., and McCullough, M.E., 2000, "Spirituality and Health: What We Know, What We Need to Know," Journal of Social and Clinical Psychology 19, 102-116.

Goldhaber, M., 2003, "With Strength of Body and Spirit: Perspectives on Healing in the Ukrainian Community," in Religious Healing in Boston: Reports from the Field, S. Saved, ed., Boston: Center for the Study of World Religions.

Greeley, A., 1997, "The Other Civic America: Religion and Social Capital," American Prospect $32,68-73$.

Gula, R.M., 1989, Reason Informed by Faith: Foundations of Catholic Morality. Mahwah, N.J.: Paulist Press.

Hackney, C.H. and Sanders, G.S., 2003, "Religiosity and Mental Health: A Meta-Analysis of Recent Studies," Journal for the Scientific Study of Religion 42, 43-55.

Harrington, D. and Keenan, J., 2003. Jesus and Virtue Ethics: Building Bridges between New Testament Studies and Moral Theology. Lanham, MD. and Chicago, IL.: Sheed and Ward.

Helliwell, J.F., and Putnam, R.D., 1999, "Education and Social Capital," NBER Working Paper 7121.

Hochschild, A.R., 1997, The Time Bind: When Work Becomes Home and Home Becomes Work. New York: Henry Holt.

Hummer, R.A., Rogers, R.G., Nam, C.B., and Ellison, C.G., 1999, "Religious Involvement and U.S. Adult Mortality," Demography 36, 273-85.

Hungerman, D.M., 2004, "Are Church and State Substitutes? Evidence from the 1996 Welfare Reform," Duke University Working Paper

Iannaccone, L.R., Finke, R., and Stark, R., 1997, "Deregulating Religion: The Economics of Church and State," Economic Inquiry 35, 350-64.

Jacobs, C., 2001, “Macht Glaube gesund?” Öffentliche Vorlesung and der Theologischen Fakultät Paderborn., http://www.cjacobs.de/.

Jung, C., 1933, Modern Man in Search of Soul. New York: Harcourt, Brace, Jovanovich.

Kark, J.D., Shemi, G., Friedlander, Y., Martin, O., Manor, O., and Blondheim, S.H., 1996, "Does Religious Observance Promote Health? Mortality in Secular vs. Religious Kibbutzim in Israel," American Journal of Public Health 86, 341-46. 
Koenig, H.G., McCullough, M.E. and Larson, D.B., 2001, Handbook of Religion and Health, Oxford: Oxford University Press.

Marmion, D., 1998, The Spirituality of Everyday Faith: A Theological Investigation of the Notion of Spirituality in Karl Rahner. Louvain: Peeters Press.

Miller, W.R., and Thoresen, C.E., 2003, "Spirituality, Religion, and Health: An Emerging Research Field," American Psychologist 58, 24-35.

Moeller, C., 2004, Church-State Separation: A Keystone to Peace, $3^{\text {rd }}$ Edition. Towanda, PA: Pennsylvania Alliance for Democracy.

New Revised Standard Version Bible, 1989, Grand Rapids: Zondervan.

O’Connell, T.E., 1990, Principles for a Catholic Morality. San Francisco: Harper \& Row.

Oswald, A.J., 1997, “Happiness and Economic Performance,” Economic Journal 107, 1815-31.

Post, J.E., 2003, “The Catholic Church Confronts its Future,” National Catholic Reporter Online, 14 February.

Powell, L.H., Shahabi, L., and C.E. Thoresen, 2003, "Religion and Spirituality: Linkages to Physical Health," American Psychologist 58, 36-52.

Putnam, R.D., 2000, Bowling Alone: The Collapse and Revival of American Community, New York: Simon \& Schuster.

St. Augustine, 1961, Confessions, London: Penguin Books.

St. Theresa of Avila, 1972, Interior Castle, A. Peers, trans., Garden City, NY: Image Books.

Schneiders, S., 1986, “Theology and Spirituality: Strangers, Rivals, or Partners?," Horizons 13, 253-74.

Schor, J.B., 1992, The Overworked American: The Unexpected Decline of Leisure. New York: Basic Books.

Sherman, R., 2005, "Reclaimed by Sabbath Rest," Interpretation: A Journal of Bible and Theology 9, 38-50.

Snowdon, D., 2001, Aging with Grace: The Nun Study and the Science of Old Age, London: The Fourth Estate.

Stark, R., and R. Finke, 2000, Acts of Faith: Explaining the Human Side of Religion. Berkeley, CA: University of California Press.

Swinyard, W.R., Kau, A-K., and Phua, H-Y., 2001, "Happiness, Materialism, and Religious Experience in the US and Singapore," Journal of Happiness Studies 2, 13-32.

van der Horst, L., 1955, “Mental Health and Religion: Whenever Man’s Life Is Estranged from God in All Its Manifestation, and Develops without Religion and Morality, There Are Grave Dangers for Mental Health," Pastoral Psychology 15-21. 
Yeung, A.B., 2004, “An Intricate Triangle - Religiosity, Volunteering, and Social Capital: The European Perspective, the Case of Finland," Nonprofit and Voluntary Sector Quarterly $33,401-22$. 